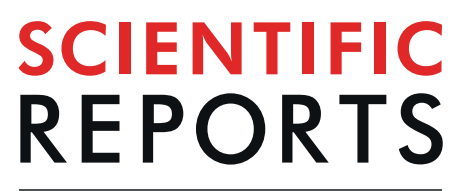

natureresearch

\title{
OPEN Author Correction: Non-invasive, Brain-controlled Functional Electrical Stimulation for Locomotion Rehabilitation in Individuals with Paraplegia
}

Aurelie Selfslagh, Solaiman Shokur, Debora S. F. Campos, Ana R. C. Donati, Sabrina Almeida, SeidiY. Yamauti, Daniel B. Coelho $\mathbb{D}$, Mohamed Bouri \& Miguel A. L. Nicolelis

Correction to: Scientific Reports https://doi.org/10.1038/s41598-019-43041-9, published online 01 May 2019

This Article contains typographical errors in the Acknowledgements section.

"This study was funded by the Brazilian Financing Agency for Studies and Projects (FINEP 01·12.0514.00), Brazilian Ministry of Science, Technology, and Innovation (MCTI). We acknowledge the National Institute of Science and Technology (INCT) Brain Machine-Interface (INCEMAQ) CNPq 573966/2008-7 of Brazilian Ministry of Science, Technology, and Innovation (MCTI/CNPq/FNDCT/CAPES/FAPERN). We want to thank Neiva Paraschiva, Adriana Ragoni, Andrea Arashiro, Maria Cristina Boscarato, Fabio Asnis, Nathan Rios, Dr. Tiago Kunrath, and Susan Halkiotis (Duke University) for their work, help, and support for this study. We finally want to thank the patients for their long-term commitment, and their trust in this research and our team."

should read:

"This study was funded by the Brazilian Financing Agency for Studies and Projects (FINEP 01·12.0514.00), Brazilian Ministry of Science, Technology, Innovation, and Communication (MCTIC). We acknowledge the National Institute of Science and Technology (INCT) Brain Machine-Interface (INCEMAQ, Siconv 704134/2009) of the National Council for Scientific and Technological Development (CNPq), Brazilian Ministry of Science, Technology, Innovation and Communication (MCTIC). Maria Cristina Boscarato, Fabio Asnis, Nathan Rios, Dr. Tiago Kunrath, and Susan Halkiotis (Duke University) for their work, help, and support for this study. We finally want to thank the patients for their long-term commitment, and their trust in this research and our team."

(i) Open Access This article is licensed under a Creative Commons Attribution 4.0 International License, which permits use, sharing, adaptation, distribution and reproduction in any medium or format, as long as you give appropriate credit to the original author(s) and the source, provide a link to the Creative Commons license, and indicate if changes were made. The images or other third party material in this article are included in the article's Creative Commons license, unless indicated otherwise in a credit line to the material. If material is not included in the article's Creative Commons license and your intended use is not permitted by statutory regulation or exceeds the permitted use, you will need to obtain permission directly from the copyright holder. To view a copy of this license, visit http://creativecommons.org/licenses/by/4.0/.

(C) The Author(s) 2019 